\title{
Digital Cities: Investigating the Image of Lagos as a Fashion City Online Through Web Search Queries
}

\author{
Morolake Dairo \\ School of Media and Communication, Pan-Atlantic University, Main Campus, Km 52 Lekki-Epe Expressway, \\ Lagos, Nigeria
}

\begin{abstract}
In the digital era, cities have to manage their brand identities on both offline and online platforms. Digital engagement has become an increasingly important strategy for cities to reach out to both locals and visitors as the internet has become a gateway linking billions of people to global careers, investments, tourism and products. Global cities are positioning their brands through elements such as fashion, music and vacation attractions to stand out even online. In recent times, the city of Lagos has been described as an emerging global fashion capital and is becoming more popular for its fashion activities and personalities. This study examines if the online image of the city on the google web search engine aligns with the city's image as an emerging fashion capital. This research employs the content analysis method, in investigating certain keywords on the google search engine. Results from this study reveal that information regarding the fashion industry in Lagos city is mostly limited to fashion weeks. It is recommended that stakeholders in the Lagos fashion industry increase visibility on online platforms including the google web search engine, which is a key portal for global information.
\end{abstract}

Keywords: keyword search, fashion capitals, Lagos city, digital cities, web search queries

DOI: 10.7176/NMMC/99-03

Publication date:October $31^{\text {st }} 2021$

\section{Introduction}

It is estimated that over 5.6 billion search queries are performed daily on the Google search engine across the globe (Skai, 2019). Search engines have become the primary portal for information globally (D'Ovidio, 2016; Godart, 2014; Larmolenko and Schneider, 2016). These portals have become a bridge, linking individuals to other individuals, jobs, experiences, cities and nations all over the world. For city administrators and its stakeholders, the search engine holds immense opportunities for global export, tourism, creative talent and much more. In recent times, the first step taken by visitors in considering and planning a trip involves the use of a search engine, to find out information about various aspects of the city including activities, its people, the weather amongst other elements (Fesenmaier, Xiang, Pan, \& Law, 2010). Therefore, cities are becoming more intentional in positioning themselves as the preferred destination for visitors, depending on their travel or migration requirements. Some cities such as Dubai have become tourist destinations, others such as Israel have positioned themselves as a religious mecca on both offline and online platforms including social media platforms. While cities such as Italy, Paris, New York and London, also known as the Big Four of fashion capitals, have positioned themselves as fashion cities by leveraging on the occurrence of fashion weeks, globally prominent fashion designers, export of fashion products and the presence of creative clusters; and amplifying these features on digital platforms including websites and social media platforms (Godart, 2014). Aside from these four fashion capitals, other emerging fashion cities such as Johannesburg, Singapore and Lagos are also gaining popularity on a global scale for their fashion activities and output (Godart, 2014; Ruth, 2021; Onyeator, 2019). In global and local media, the city of Lagos, located in Nigeria has been praised for its creative fashion talent, products and annual fashion weeks that attract stakeholders in the global fashion industry including Naomi Campbell and there are numerous studies (Bada, 2013; Oberhofer, 2012; Offiah, 2017; Onyeator, 2019) that debate and defend the emerging status of Lagos as a fashion capital based on the cities fashion activities, talent and lifestyle of the city's residents. However, it is also important to assess the image of Lagos on online platforms such as search engines. In an era, where people search for everything and for places to visit based on their interests, this study seeks to explore if the fashion city status that is gradually being associated with Lagos resonates with the search results of the city on search engines.

\section{Literature Review}

\subsection{Digitization and the Global fashion industry}

Fashion capitals are an attraction to investors and entrepreneurs as the success of fashion businesses in these cities attract more budding entrepreneurs to this sector. Ralph Lauren, Calvin Klein, and Marc Jacobs are globally renowned fashion labels based in New York but have since expanded by locating their outlets in other countries, based on their success and acceptance in their New York headquarters. Digitization is contributing to the growth of the fashion industry as well as the creation of more fashion capitals. Global brands are extending to other cities, while local brands have a more international mindset hence expanding their competition and 
market base. E-commerce platforms like Etsy and the SME Market hub are changing the consumption process of fashion goods. Industrie Africa is a digital showroom focused on bridging the gap between the African fashion industry and the world; it aims to link African designers to fashion merchandisers and customers from all over the globe. Individual merchandisers can sell directly to fashion consumers without the traditional distribution channels, resulting in low cost of distribution and expanding reach to global customers (Joint Economic Committee. United States Congress, 2016). Digitization is bridging the logistics gap in the African fashion industry as mobile technology is being integrated into the user experience due to the rising growth of internet access in the continent (Africa, n.d; Ba, 2015).

Hasanaj (2017), points out some digital trends that are becoming eminent in the fashion industry in every process of the value chain. Mobile marketing is a key channel of promoting fashion products and personalities and has been influential in the adoption of eCommerce strategies. Most fashion websites are mobile-optimised as customers increasingly access information on their smartphones. Secondly, the customer experience in physical and online stores is also transforming as global fashion stores use more technological interactions such as selfcheckout technology to optimise brand-consumer interaction. Another key trend that has influenced other sectors, as well as the fashion industry, is social media. These platforms are changing the supply chain of the fashion industry. Previously exclusive fashion shows can now be viewed live or post-event through virtual reality software, allowing consumers experience a close-to-reality fashion show. Digital engagement is a key aspect of fashion marketing campaigns. Instagram, Facebook, Tiktok, Twitter are some of the major platforms used by these fashion brands, as they are highly visual and involve consumer engagement (Hope, 2016).

In cities like Lagos where fashion weeks are still evolving and not all brands participate based on their market positioning or the costs involved, websites and social media platforms are key in reaching out to a wide variety of customers. With eCommerce enabled features on social media and chat platforms (e.g Whatsapp), customers can shop directly from such pages and experience the brand online and also get to read reviews of other customers. These platforms also double as a consultation platform, as fashion designers engage customers on styles, measurement, sizing, and delivery without face to face contact.

All these changes in digital technology and consumer behaviour have contributed to the increase and dependence of global customers on web search engines to find information on a wide variety of topics including travel and purchase of fashion products. Pan, Xiang, Law, and Fesenmaier (2010) note that the usage of search engines is a two-fold cognitive process: query formulation and user evaluation. In the query formulation phase, a query is inputted in the search engine. The results of the search are usually determined by the users' knowledge of search engine mechanisms, their understanding of the field and the keyword being searched. At the user evaluation phase, the results of the first keyword search determine if the user continues the search by rephrasing their keywords or clicking additional web pages linked to the previous search. These search queries can be categorised into navigational, informational, and transactional goals as users are focused on finding a place, knowing more about an issue or have the objective of purchase when they commence their web searches (Jansen \& Molina, 2006; Xiang, Gretzel, \& Fesenmaier, 2009). The search engine is the key source of the content as it is employed by users in finding information about places and their characteristics and this study is focused on exploring the representation of Lagos as a fashion city on these platforms.

\section{Methodology}

\subsection{Methodological Review}

Exploring search engines through content analysis is relatively new and there seems to be no generally accepted theoretical framework on its application in academia. Hence, it is important to review how various authors have used content analysis in analysing content from web searches to achieve their research goals. This will help in laying a foundation on how this methodology will be used to achieve the objectives of this study.

In the research conducted by Ribisi, Lee, Henriksen, and Haladjian (2003), content analysis was used in examining keyword searches online to investigate the promotion of smoking culture and lifestyles on websites, especially to youths. They deployed unstructured content analysis in examining the websites. Certain keywords were inputted into the Yahoo! Search engine and three units of analysis were used; content featured on the Web site main pages, content featured on the website pages and pictures that appeared on the main website page or were a click away from the main website page. The websites were downloaded before coding on a selected date to ensure the currency of data during the period of coding.

Content analysis was also adopted by Larmolenko and Schneider (2016) in their research, "Destination Image Representation Online: Content Analysis of Ukraine Travel Related Websites," to probe the online representation of Ukraine to global tourists using keyword searches. The metrics were developed atheoretically from a review of related literature and exploratory examination. In their study, nine subcategories were defined through a combination of the city's keywords and nine other keywords associated with tourism such as shopping, culture, food, and history. After the web search of the keywords, the top ten travel-related websites were selected per subcategory resulting in a total of 90 websites. These 90 websites were eventually shortlisted to about 64 
websites after the elimination of recurring and unworkable websites. The textual data from these sites were then analysed through the CATPAC softtware, to understand how the content portrayed Ukraine to tourists.

In another study also focused on destination branding, Xiang \& Pan (2011) utilised content analysis to investigate how individuals in the United States (US) search for cities and the impact of these searches on tourism marketing on online platforms. Previous queries inputted by users from old transaction logs derived were sourced from various search engines including Excite, AllTheWeb and AltaVista. Results from the study showed that irrespective of the location of the user, most of the users utilised similar keywords when it comes to travel-related searches for cities within the US.

\subsection{Methodology for This Study}

Leveraging on the research conducted by other researchers in this field (as identified in the methodological review), the content analysis method was used in examining selected keywords inputted in the Google search engine chosen. Google was the only search engine used as it has been rated the top search engine in the world with a majority of users selecting it over Yahoo! And Bing.Com (Heitzman, 2017; Pan, Xiang, Law, \& Fesenmaier, 2010). In selecting the keywords to be inputted in the search engine for this study, specific keywords common to global fashion cities (Godart, 2019) including events, designers, magazines, education were included in addition to the city name e.g Lagos + fashion events, Lagos + fashion designers. The keywords selected involved all the links with dominant themes that reflect the keywords, Lagos Fashion theme when typed in the search engine under the section header All on the Google search engine. In analysing the web pages, the search results from the first two pages on the Google search engine were analysed using the keyword Lagos fashion, in addition to other keywords that can be associated with global fashion cities (Lagos fashion event, Lagos fashion fair, Lagos fashion designers, Lagos fashion industry, Lagos fashion magazines, Lagos fashion education, Lagos garment district/ textile industry) all conducted between the last quarter (September - October) of 2019 before the COVID-19 pandemic.

The analysis of the keywords inputted into the search bar was restricted to the first two pages on the google search page, as research has shown that search engine users limit their searches to three pages per search on both mobile and desktop (Advanced Web Ranking, 2019; Mangles, 2018; Spink \& Jansen, 2004). This decision to select only the first two pages was also supported with the results from the pilot which showed that after examining the first three pages on Google resulted in repeated links and data management was more difficult, hence this study was limited to the first 2 pages of enquiry on Google search. Thereafter, all the links on the first two pages of the Google search bar were opened. These links were opened in a new tab and there was a fast reading (or viewing of videos as the case may be) to have an idea of the type of content on these links.

A guest account on Google was used in exploring the google search engine to ensure there was no browser history or cookies to influence web search results. Links relating to paid search advertising, organic search google places and paid search were ignored. Therefore, only the organic search algorithmic results were collated. The results from such searches from the All tab on Google was analysed and inputted in an excel sheet based on the categories, keyword title, author, source, year, location (local or global), a summary of information and other featured snippets. These coding sheets on excel were used in examining the keywords inputted in the search bar.

A single rater, who had practised with coding based on learning from various studies and content analysis workbooks singlehandedly coded the websites and information from the pages and duplicates of web links were removed at this stage. It is important to note that this study was conducted in Nigeria and a web search from another country VPN may show slightly different results.

Keywords relating to Lagos city and Lagos fashion were inputted into the search bar (Lagos fashion, Lagos fashion event, Lagos fashion fair, Lagos fashion designers, Lagos fashion industry, Lagos fashion magazines, Lagos fashion education, and Lagos fashion district/ textile industry). The results from such searches from the All tab on Google was analysed and inputted in an excel sheet based on the categories, keyword title, author, source, year, location (local or global), a summary of information and other featured snippets.

\section{Discussion of Findings}

In total, 143 web pages were derived from the keyword search results associated with the theme Lagos fashion. These results will be presented using tables and will be discussed in subsequent sections below.

\subsection{Content Analysis of Keyword Lagos Fashion}

Table 1 shows the keyword search results for the main theme Lagos Fashion. The results of the searches in the first two pages of the Google search bar revealed that Lagos Fashion Week, also known as LFW (one of the most popular fashion events in the city) resulted in 17 (58.6\%) results from the Google search, while $4(13.7 \%)$ of the searches were related to Lagos fashion fairs. The keyword, Lagos fashion events resulted in $3(10.3 \%)$ of the searches while $1(3.4 \%)$ of the searches resulted in Lagos fashion styles. Other search results from the keyword search displayed articles relating to GTB fashion weekend, Nigerian fashion, Nigerian fashion events and 
shopping. These searches indicate that one of the most prominent elements of the Lagos fashion industry is the occurrence of fashion weeks, as $L F W$ (Lagos fashion week) seems to have been featured in a lot of global and local media, hence its predominant feature on multiple web pages.

Table 1. Keyword Search Results for Lagos Fashion

\begin{tabular}{|c|c|c|}
\hline Lagos Fashion Keyword Search Results & Frequency & Percentage (\%) \\
\hline GTB Fashion Weekend & 1 & $3.4 \%$ \\
\hline Lagos Fashion Events & 3 & $10.3 \%$ \\
\hline Lagos Fashion Fair & 4 & $13.7 \%$ \\
\hline Lagos Fashion Styles & 1 & $3.4 \%$ \\
\hline LFW & 17 & $58.6 \%$ \\
\hline Nigerian Fashion & 1 & $3.4 \%$ \\
\hline Nigerian Fashion Events & 1 & $3.4 \%$ \\
\hline Shopping & 1 & $3.4 \%$ \\
\hline Total & 29 & $100 \%$ \\
\hline
\end{tabular}

\subsection{Content Analysis of Keyword Search, Lagos Fashion Designers}

Table 2 shows the keyword search results for Lagos Fashion Designers. The keyword search for this category mostly reveals information on Lagos fashion designers $(44.4 \%)$ and $L F W(33.3 \%)$. It seems that fashion designers headquartered in Lagos Nigeria, included the city in their brand description and designer bio during media interviews and they also included details of Lagos city on their owned websites. The Lagos fashion week also works closely with fashion designers in Lagos and continues to feature them on their official website, which was also prominent in the keyword search results. However, $F A D A N$, which has described itself as the official association for fashion designers in Nigeria (FADAN, n.d.) only resulted in $1(5.5 \%)$ of the results showed. Affiliation of the Nigerian country brand with the city brand was also observed in the keyword search results in this category as $3(16.6 \%)$ of the searches resulted in Nigerian fashion designers, even though the keyword search was limited to designers within Lagos city.

Table 2. Keyword Search Results for Lagos Fashion Designers

\begin{tabular}{|c|c|c|}
\hline Lagos Fashion Designers Keyword Search Results & Frequency & Percentage (\%) \\
\hline FADAN & 1 & $5.5 \%$ \\
\hline Lagos Fashion Designers & 8 & $44.4 \%$ \\
\hline LFW & 6 & $33.3 \%$ \\
\hline Nigerian Fashion Designers & 3 & $16.6 \%$ \\
\hline Total & 18 & $100 \%$ \\
\hline
\end{tabular}

4.3 Content Analysis of Keyword Search, Lagos Fashion Industry

In Table 3, The $L F W$ ranks highest in the keyword search accounting for $5(26.3 \%)$ of the results, followed closely by activities related to Lagos fashion fairs $(21.0 \%)$. Other results led to information on the Nigerian fashion industry $(21.0 \%)$ while only $2(10.5 \%)$ of the searches resulted in Nigerian fashion designers. Other fashion weeks such as Arise fashion week and GTB fashion weekend accounted for only 1 (5.2\%) of the keyword searches respectively. Again, fashion weeks are prominent in this search. A sample keyword search on other cities termed as global fashion cities such as New York and London reveal search results that give a more holistic look at the fashion industry. The results involve content focused on job creation and various reports on the local and global supply chain within the fashion industry of these cities.

Table 3. Keyword Search Results for Lagos Fashion Industry

\begin{tabular}{|c|c|c|}
\hline Lagos Fashion Industry Keyword Search Results & Frequency & Percentage (\%) \\
\hline African Fashion Industry & 1 & $5.2 \%$ \\
\hline Arise Fashion Week & 1 & $5.2 \%$ \\
\hline GTB Fashion Weekend & 1 & $5.2 \%$ \\
\hline Lagos Fashion Events & 1 & $5.2 \%$ \\
\hline Lagos Fashion Fair & 4 & $21.0 \%$ \\
\hline LFW & 5 & $26.3 \%$ \\
\hline Nigerian Fashion Designers & 2 & $10.5 \%$ \\
\hline Nigerian Fashion Industry & 4 & $21.0 \%$ \\
\hline Total & 19 & $100 \%$ \\
\hline
\end{tabular}

4.4 Content Analysis of Keyword Search, Lagos Fashion Magazines

Table 4 shows the keyword search results for Lagos Fashion Magazines. Even though the $L F W$ is a fashion week, it accounted for $10(52.6 \%)$ of the search results for magazines while $4(21.0 \%)$ of the web search results led to 
website pages and blogs involving lifestyle magazines. This shows the state of the Lagos fashion media online, as newspapers insets and lifestyle magazines are still the major channels for fashion (Nwafor, 2011). Though some online web magazines such as Schick and Bella Naija have described themselves as lifestyle and fashion magazines, it still seems there is no Nigerian or Lagos based magazine solely focused on fashion content, such that the content and structure can compete with the likes of global fashion magazines such as Vogue or Elle.

Table 4. Keyword Search Results for Lagos Fashion Magazines
\begin{tabular}{|l|c|l|}
\hline $\begin{array}{c}\text { Lagos Fashion Magazines } \\
\text { Search Results }\end{array}$ & Frequency & Percentage (\%) \\
\hline Fashion Trends & 1 & $5.2 \%$ \\
\hline Lagos Fashion Designers & 1 & $5.2 \%$ \\
\hline Lagos Fashion Trends & 1 & $5.2 \%$ \\
\hline LFW & 10 & $52.6 \%$ \\
\hline Lifestyle Magazine & 4 & $21.0 \%$ \\
\hline Nigerian Fashion Designers & 1 & $5.2 \%$ \\
\hline Others & 1 & $5.2 \%$ \\
\hline Total & $\mathbf{1 9}$ & $\mathbf{1 0 0 \%}$ \\
\hline
\end{tabular}

4.5 Content Analysis of Keyword Search, Lagos Fashion Schools

Table 5 shows the keyword search results for Lagos Fashion Schools. Even though 17 (89.4\%) of the results showed Lagos fashion schools, it is worthy to note that most of the links from the search engine results, led to personal blogs, websites and directories of informal fashion schools and not fashion universities. This reveals the gap in fashion education in Lagos and Nigeria in general, especially since one of the major technical Universities in Lagos, YABATECH did not show up in the search results, even though they offer government-accredited courses in fashion studies.

Table 5. Keyword Search Results for Lagos Fashion Schools

\begin{tabular}{|c|c|c|}
\hline Lagos Fashion Schools & Frequency & Percentage (\%) \\
\hline Lagos Fashion Schools & 17 & $89.4 \%$ \\
\hline Nigerian fashion school & 1 & $5.2 \%$ \\
\hline Others & 1 & $5.2 \%$ \\
\hline Total & 19 & $100 \%$ \\
\hline
\end{tabular}

4.6 Content Analysis of Keyword Search, Lagos Fashion Districts

Table 6 shows the keyword search results for "Lagos Fashion Districts". The keyword search resulted in a wide range of outcomes that can be categorized under the following themes, Lagos city, Lagos fashion boutiques, Lagos fashion fair, Lagos fashion trends amongst others. Results for this keyword reveal that fashion districts may not be a popular theme for Nigeria fashion. Therefore, for future studies, it is suggested that other keywords such as markets or centres be used.

Table 6. Keyword Search Results for Lagos Fashion District

\begin{tabular}{|c|c|c|}
\hline Lagos Fashion District & Frequency & Percentage (\%) \\
\hline Lagos city & 1 & $5.2 \%$ \\
\hline Lagos Fashion Boutiques & 1 & $5.2 \%$ \\
\hline Lagos Fashion Centers & 1 & $5.2 \%$ \\
\hline Lagos Fashion Events & 1 & $5.2 \%$ \\
\hline Lagos Fashion Fair & 2 & $10.5 \%$ \\
\hline Lagos Fashion Schools & 1 & $5.2 \%$ \\
\hline Lagos Fashion Stakeholder & 2 & $10.5 \%$ \\
\hline Lagos Fashion Trends & 1 & $5.2 \%$ \\
\hline Lagos Market & 1 & $5.2 \%$ \\
\hline Lagos Shopping Centre & 1 & $5.2 \%$ \\
\hline LFW & 1 & $5.2 \%$ \\
\hline Nigerian Fashion & 2 & $10.5 \%$ \\
\hline Others & 4 & $21.0 \%$ \\
\hline Total & $\mathbf{1 9}$ & $\mathbf{1 0 0 \%}$ \\
\hline
\end{tabular}




\subsection{Content Analysis of Keyword Lagos Fashion Events}

In the table below (Table 7), the majority of the keyword searches resulted in $L F W(38.8 \%)$, followed by events related to Lagos fashion fairs. The other searches resulted in other events unrelated to fashion but located in Lagos while $1(5.5 \%)$ of the searches related to fashion events happening in Nigeria. Other fashion weeks such as the Arise fashion week or GTB fashion week were not featured in the results, despite their annual occurrence in previous years.

Table 7. Keyword Search Results for Lagos Fashion Events

\begin{tabular}{|c|c|c|}
\hline Lagos Fashion Events & Frequency & Percentage (\%) \\
\hline Nigeria fashion events & 1 & $5.5 \%$ \\
\hline Lagos fashion fair & 4 & $22.2 \%$ \\
\hline Events in Lagos & 2 & $11.1 \%$ \\
\hline Events in Nigeria & 1 & $5.5 \%$ \\
\hline LFW & 7 & $38.8 \%$ \\
\hline Other Lagos fashion events & 3 & $16.6 \%$ \\
\hline Total & $\mathbf{1 8}$ & $\mathbf{1 0 0 \%}$ \\
\hline
\end{tabular}

It is important to establish the source of keyword search results for "Lagos fashion" as shown in Table 8 . The sources show the publishers and authors of most of the web pages resulting from the keyword search are mostly from News/ information platforms (29.3\% - 42 search results). Event information and registration platforms contributed to $7(11.8 \%)$ of the search results while $15(10.4 \%)$ of the keyword searches were traced to Business directories/information and networking platforms. LFW contributed $9(6.2 \%)$ search results related to Lagos fashion while Fashion schools contributed 8 (5.5\%) of the keyword search results. Fashion \& lifestyle magazines contributed to $5(3.4 \%)$ of the sources while $F A D A N$ contributed to only $1 \quad(0.6 \%)$ source for the search results. These results show the power of the media as a major source of information even on online platforms. More collaborations with fashion industry stakeholders will help in perpetuating Lagos fashion narratives within the local and global sphere.

Table 8. Sources of Keywords related to Lagos Fashion

\begin{tabular}{|l|l|l|}
\hline \multicolumn{1}{|c|}{ Types of Web Pages } & \multicolumn{1}{c|}{ No } & \multicolumn{1}{c|}{$\begin{array}{c}\text { Percentage } \\
\text { (\%) }\end{array}$} \\
\hline Academic site & 4 & $2.7 \%$ \\
\hline Book & 1 & $0.6 \%$ \\
\hline Business directory/ info/ networking platform & 15 & $10.4 \%$ \\
\hline eCommerce site & 3 & $2.0 \%$ \\
\hline Event information/registration platform & 17 & $11.8 \%$ \\
\hline Social media (FB, Twitter, Youtube) & 3 & $2.0 \%$ \\
\hline FADAN & 1 & $0.6 \%$ \\
\hline fashion \& lifestyle magazine & 5 & $3.4 \%$ \\
\hline Fashion Designer & 2 & $1.3 \%$ \\
\hline Fashion School & 8 & $5.5 \%$ \\
\hline Global fashion magazine & 6 & $4.1 \%$ \\
\hline Government website & 3 & $2.0 \%$ \\
\hline GTB & 2 & $1.3 \%$ \\
\hline LFF & 5 & $3.4 \%$ \\
\hline LFW & 9 & $6.2 \%$ \\
\hline Magazine & 1 & $0.6 \%$ \\
\hline Music streaming site & 1 & $0.6 \%$ \\
\hline News/information platform & 42 & $29.3 \%$ \\
\hline Personal Blog & 2 & $1.3 \%$ \\
\hline Private business & 5 & $3.4 \%$ \\
\hline Shopping mall website & 1 & $0.6 \%$ \\
\hline Travel site/ mag & 4 & $2.7 \%$ \\
\hline Pages Not found & 3 & $2.0 \%$ \\
\hline Total & & $100 \%$ \\
\hline
\end{tabular}

\section{Summary of Results}

The findings from this study reveal that there is a shortage of information, as regards content relating to the Lagos fashion industry based on the keywords used for this study, and there seems to be a low alignment between the content found online and the status of Lagos city as a fashion capital. The search results revealed 
minimal data on the Lagos fashion industry in its entirety. There was little or no information leading to research on the economic and social value of the fashion industry. It is worthy to note that the Google Scholar search engine was not used for this study, hence the absence of academic articles in the search results. It was further observed that the city seems to be most popular for the Lagos fashion week, on the google search engine. Even though global fashion cities are known for other features such as their fashion designers, fashion institutions, fashion districts and fashion magazines, amongst others. In addition, other popular fashion weeks in Lagos such as Arise fashion week and the GT fashion weekend were not prominent in the search results.

The analysis of the results also revealed a strong link between the Lagos fashion industry and the Nigerian fashion industry. This corroborates the connection between the city and country brand as many of the keyword search results revealed information about the Nigerian fashion industry in general.

The results from this study also seem to show low search engine optimization by Lagos fashion designers to promote the visibility of their businesses. Their websites, blogs and eCommerce pages seemed to contribute minimally to the sources of the keyword for this study and the keyword search for Lagos fashion designers, resulted in mostly news reports and interviews and not information causally linked to their businesses. This further revealed that the media are a key source for information on the Lagos fashion industry even though there is still no "fashion magazine" linked to Lagos city. It is also important to note that the sources of information for this keyword feature minimal information about Lagos State or the Nigerian government websites or web links. For other global fashion cities such as New York and London, it is obvious that there is a promotion of the fashion industry by government bodies such as the NYEDC (New York City economic development) and the British fashion council.

\section{Conclusion}

The digital footprint of a city and its industry is vital to the positioning of the city and any aspect of the city, the city administrator and its internal stakeholders wish to promote to visitors and investors. In partnership with residents and business owners in Lagos, there must be an intentional agenda to promote the association of the city with fashion, as the city of Lagos has been recognized as an emerging global fashion capital, and this is an opportunity to leverage this sector to create jobs and drive economic growth for the city. Aside from the local media, relevant government bodies must also continue to drive the narrative of creative industries on their digital platforms including their websites. This means that there needs to be constant updates and happenings in the news about the creative industries including the Lagos fashion industry from various perspectives to ensure consistency and currency.

Beyond their annual fashion weeks, global fashion capitals are popular for other fashion activities and elements such as the presence of fashion magazines and their globally renowned fashion designers. On online platforms, the Lagos fashion industry needs to make more efforts to remain visible beyond their annual fashion weeks and reinforce other aspects of the industry such as their products, talents, supply chain and fashion influencers. There is an opportunity for fashion designers and producers of other fashion products in Lagos to create other experiences aside from the fashion week and also position their products and businesses to a global audience.

In addition, the stakeholders in the Lagos fashion industry, including the Lagos State government must also work on building and consistently nurturing their identities online on both local and global platforms. Aside from contributing to the online identity of the city in relation to fashion, it also opens more opportunities for global collaboration and exports. Fashion designers will also need to update their websites or have a blog on curated content that appeals to fashion enthusiasts on a global scale. A recognized fashion magazine with a widely circulated online edition will also help to tell the story of the fashion industry in Lagos.

For future studies, it is recommended that the identity of the city of Lagos (not limited to a particular image) is analysed online using keywords collated from both residents and tourists to establish the digital image and presence of Lagos city on web search engines and social media platforms. In retrospect, a comparative study amongst cities will also help to establish the standard of online marketing and search engine marketing for global cities.

The online identity of Lagos city is crucial to the growth of the Lagos fashion industry and its perception by both internal and external stakeholders. The adoption and efficient use of content marketing and search engine optimization strategies can further boost the image of Lagos city as an emerging fashion capital. The search engine has become a key information portal for cities and the quality of information and ease in finding information can negatively or positively influence the decisions of visitors, residents and investors in selecting a city to visit, migrate to and also perform global transactions.

\section{References}

Advanced Web Ranking. (2019, February). Google organic CTR history. Retrieved from Advanced Web Ranking: https://www.advancedwebranking.com/ctrstudy/ 
Bada, O. (2013). The emerging role of fashion tourism and the need for a development strategy in Lagos, Nigeria. Case Study: Lagos Fashion and Design Week (Unpublished Masters Thesis). Kokkola: Centria University of Applied Sciences.

Bruzzi, S., \& Gibson, P. C. (2004). 'Fashion is the fifth character': Fashion, costume and character in Sex and the City. In K. Akass, \& J. McCabe (Eds.), Reading Sex and the City (pp. 115-129). London; New York: I.B Taurus.

D'Ovidio, M. (2016). The creative city does not exist. Criticla essays on the creative and cultural economy of cities. Milano: Ledizioni.

FADAN. (n.d.). About Us. Retrieved August 2019, from Fadan: http://fadan.ng/

Fesenmaier, D. R., Xiang, Z., Pan, B., \& Law, R. (2010). An analysis of search engine use for travel planning. Information and Communication Technologies in Tourism, ENTER 2010, Proceedings of the International Conference (pp. 1 - 42). Lugano: DBLP.

Godart, F. (2014). The power structure of the fashion industry: Fashion capitals, globalization and creativity. International Journal of Fashion Studies, 1(1), 39 - 55.

Jansen, B., \& Molina, P. (2006). The effectiveness of web search engines for retrieving relevant eCommerce links. Information Processing and Management, 42(4), 1075 - 1098.

Larmolenko, S., \& Schneider, P. (2016). Destination image representation online: Content analysis of Ukraine travel related website. Travel and Tourism Research Association: Advancing Tourism Research Globally, 10. Retrieved https://scholarworks.umass.edu/cgi/viewcontent.cgi?referer=https:/www.google.com/\&httpsredir=1\&articl $\mathrm{e}=1453$ \& context $=$ ttra

Mangles, C. (2018, January). Search Engine Statistics 2018. Retrieved from Smart Insights: https://www.smartinsights.com/search-engine-marketing/search-engine-statistics/

Nwafor, O. (2011). Aso Ebi: Fashioning self through photography and "fashion" magazines in Nigeria. Creative Artist: A Journal of Theatre and Media Studies, 6(1), 1 - 36.

Oberhofer, M. A. (2012). Fashioning African Cities: The case of Johannesburg, Lagos and Douala. Streetnotes, $20,65-89$

Offiah, C. A. (2017). Globalization and the culture/creative industries: An assessment of Nigeria's position in the global space. IOSR Journal Of Humanities And Social Science (IOSR-JHSS), 22(1), 11-23.

Onyeator, I. (2019). Class structures in the creative industries: An analysis of the working conditions of workers in Nigeria's fashion sector. Research on Humanities and Social Sciences, 9(4).

Pan, B., Litvin, S., \& Goldman, H. (2006). Real Users, Real Trips, and Real Queries: An Analysis of Destination Search on a Search Engine. Annual Conference of Travel and Tourism Research Association, (pp. 1-7). Dublin.

Pesonen, J., \& Pasanen, K. (2017). a closer look at tourist information search behaviour when travelling abroad: What is the role of online marketing in choice of destination? In R. Schegg, \& B. Stangl (Eds.), Information and Communication Technologies in Tourism 2017 (pp. 431-443). Cham: Springer.

Ribisi, K. M., Lee, R., Henriksen, L., \& Haladjian, H. H. (2003). A content analysis of websites promoting smoking culture and lifestyle. Health Education \& Behaviour, 30(1), 64 - 78.

Ruth, P. A. (2021). Fiscal aspects of the fashion industry: The Big Four global capitals and the Nigerian equivalent. Open Journal of Social Sciences, 2021(9), 232-242.

Skai. (2019, February 25). Google Search Statistics. Retrieved October 1, 2021, from Internet Live Stats: https://skai.io/monday-morning-metrics-daily-searches-on-google-and-other-google-facts/

Spink, A., \& Jansen, B. J. (2004). A study of web search trends. Webology, 1(2), Article 4. Retrieved from http://www.webology.org/2004/v1n2/a4.html

Xiang, Z., \& Pan, B. (2011). Travel queries on cities in the United States: Implications for search engine marketing for tourist destinations. Tourism Management, 32(1), 88-97.

Xiang, Z., Gretzel, U., \& Fesenmaier, D. (2009). Semantic representation of the online tourism domain. Journal of Travel Research, 47(4), 440 - 453. 